\title{
Immune tolerance to asymptomatic submicroscopic Plasmodium falciparum infections in adults living in malaria endemic areas
}

Babacar BD Diouf ( $\sim$ Babacar.Diouf@pasteur.sn )

Institut Pasteur de Dakar https://orcid.org/0000-0003-0391-883X

Fode Diop

Institut Pasteur de Dakar

Yakhya Dieye

Institut Pasteur de Dakar

Adja Fatou Mbodji

Institut Pasteur de Dakar

Cheikh Talla

Institut Pasteur de Dakar

Alassane Thiam

Institut Pasteur de Dakar

Ibrahima Dia

Institut Pasteur de Dakar

Joseph Faye

Institut Pasteur de Dakar

Mbacké Sembène

Universite Cheikh Anta Diop Faculte des Sciences et Techniques

Inès Vigan-Womas

Institut Pasteur de Dakar

Fatoumata Diène Sarr

Institut Pasteur de Dakar

Ronald Perraut

Institut Pasteur de Dakar

Aïssatou Toure-Balde

Institut Pasteur de Dakar

Makhtar Niang

Institut Pasteur de Dakar

Research 
Keywords: Malaria, immune tolerance, submicroscopic parasite carriage, asymptomatic, Plasmodium falciparum, Senegal

Posted Date: July 28th, 2020

DOI: https://doi.org/10.21203/rs.3.rs-48815/v1

License: (c) (1) This work is licensed under a Creative Commons Attribution 4.0 International License. Read Full License 


\section{Abstract}

Background Combined malaria control interventions have reduced mortality rate, number of clinical cases and parasite prevalence across Africa between 2000 and 2015. As a consequence, Plasmodium infections have become mostly asymptomatic and often sub-microscopic in many endemic areas. The present study aims to evaluate the contribution of asymptomatic sub-microscopic $P$. falciparum carriage on antibody responses against malaria antigens.

Methods A total of 353 samples from a cross-sectional sampling conducted in Ndiop (Senegal) in 2016 were tested by qPCR and microscopy to determine parasite prevalence. Plasmodium falciparum positive samples were genotyped using $m s p-2$ marker. The IgG seroprevalence against crude schizont antigen of a local $P$. falciparum strain, tested by ELISA, was compared to parasite prevalence. An age-matched, under 10 years, $10-15$ and over 15 years cohort of 110 positive and negative qPCR samples were used to determine the impact of sub-microscopic carriage on $\lg \mathrm{G}$ and $\lg \mathrm{M}$ antibody responses against schizont extract and MSP3 recombinant antigen.

Results The microscopic diagnosis was negative for all thick smears defining a study cohort of submicroscopic asymptomatic individuals with an overall parasite prevalence of $22.37 \%(79 / 353)$ by qPCR. Submicroscopic infections were associated with significant lower IgG responses in qPCR positive samples for individuals over 15 years of age, for both crude schizont $(p=0.021)$ and MSP3 recombinant antigen $(p=0.035)$. IgM responses were significantly higher $(p=0.034)$ in children under 10 years, showing their susceptibility to primary infection. Above 15 years of age, a significant difference was found between parasite prevalence of $9.3 \%(33 / 353)$ and IgG seroprevalence of $23.8 \%(84 / 353)(p=0.01)$. The overall genetic diversity detected is characterized by a complexity of infection (COI) and a number of genotypes of 2.4 and 17 , respectively.

Conclusion Asymptomatic submicroscopic $P$. falciparum carriage is prevalent in the study area and is associated with immune tolerance to parasites in adults. The difference between parasite prevalence and IgG seroprevalence results from long-lived IgG in adults point out attention for elders in endemic areas as a stable parasite reservoir. In this context, mass molecular detection followed by treatment could be a valuable method for achieving elimination.

\section{Introduction}

Malaria is a major health concern in endemic countries, causing 228 million cases and 405, 000 deaths in 2018 [1]. Nevertherless, the burden of malaria has decreased over the past 15 years due to sustained investment in malaria control programs. These programs had a greater impact in Africa, which supports $93 \%$ of the global malaria morbidity and mortality [1]. As a result, the mortality rate fell by $57 \%$ in subSaharan Africa between 2000 and 2015 [2]. At the same time, the parasite prevalence and the number of malaria cases have decreased by $50 \%$, while mortality declined by $40 \%$ across Africa. The overall decline of malaria prevalence is attributed for $60 \%, 19 \%$ and $13 \%$ to widespread use of insecticide-treated nets 
(ITNs), treatment with artemisinin-based combination therapies (ACTs) and indoor residual spraying (IRS) respectively [3]. The scaling-up of interventions on several fronts has led to a decrease in transmission, which, although heterogeneous, has profoundly changed the epidemiology of malaria in Africa $[3,4]$.

The intensity of malaria transmission can be directly measured by the entomological inoculation rate (EIR) [5], but generalization of EIR is limited by its cost and the wide variation observed even within a single locality $[6,7]$. EIR is also influenced by factors such as temperature, rainfall and urbanization [8]. Therefore, to overcome these limitations, parasite carriage in children aged 2-10 years was used to epidemiologically classify regions as there is a strong correlation between parasite prevalence and EIR [4]. However, some studies failed to establish a link between parasite prevalence and EIR [9]. For this reason, seroprevalence of antibodies to malaria antigens has also been considered to evaluate the burden of malaria $[10,11]$. Both parasite prevalence and seroprevalence reflect the history of malaria and can be used to infer changes in transmission over time $[10,11,13]$. Seroprevalence is less affected by seasonal and local variations and reflects more recent changes in malaria exposure [10,12]. Overall antibody responses to malaria antigens have proven to be a very useful epidemiological tool for monitoring transmission $[14,15]$.

Measurement of prevalence and seroprevalence has shown that malaria control interventions have favored transition from high to low transmission in many endemic areas [16]. As a consequence, most of Plasmodium infections are asymptomatic in these regions $[17,18]$. Asymptomatic malaria can be classified as microscopic or submicroscopic depending on whether the parasite can be detected by thick blood smears examination or not.

Antibodies against Plasmodium antigens are associated with protection against clinical malaria in endemic areas [19,20]. These antibodies are involved in mechanisms such as inhibition of invasion [21], parasite opsonization [19, 22], and complement mediated lysis of infected red blood cells [23].

Antimalarial immunity is also linked to reduced failure of malaria treatment in endemic regions [24].

To date, little information is available about submicroscopic asymptomatic carriage of Plasmodium in relation with the acquisition of antimalarial immunity. Therefore, understanding the role of submicroscopic asymptomatic parasites in the immune response could contribute to the development of effective vaccine $[25,26,27]$ or treatment $[28]$ towards malaria elimination.

In this study, we analyzed the contribution of asymptomatic submicroscopic carriage of $P$. falciparum on IgG and IgM responses to malaria antigens. We examined the association between parasite prevalence and IgG seroprevalence. We also studied the genetic diversity associated with these asymptomatic submicroscopic infections.

\section{Methods}

\section{Study site}


This study is part of an ongoing program initiated in the villages of Dielmo and Ndiop (Fatick region, Senegal) in 1990 and 1993 respectively. The project consists of long-term investigations on host-parasite relationships and the study of the mechanisms of protective immunity against malaria [29]. Ndiop is located $280 \mathrm{~km}$ from the capital Dakar and about $15 \mathrm{~km}$ north of the Gambian border. At the beginning of the study, Ndiop was a mesoendemic area with a moderate seasonal malaria transmission [30]. Vector control was implemented in July 2008 and long-lasting insecticide-treated nets (LLINs) were provided to each household [31]. The EIR was estimated to 20 infective bites/person/year in 1993 [32], 79 in 2000 and 4.6 in 2010 [33]. Microscopic parasite prevalence followed the same trend as EIR with $50 \%, 7 \%$ [33], $0.27 \%$ and $0 \%$ [34] in 2000, 2010, 2014 and 2015 respectively. From 2014, parasite prevalence in Ndiop has become predominantly submicroscopic with community-based prevalence estimated by qPCR to $12.5 \%$ and $6.4 \%$ in 2014 and 2015 , respectively. The majority of these infections (95.5\%) were due to $P$. falciparum [34].

\section{Ethical consideration}

The Dielmo/Ndiop project was approved by the Senegalese Ministry of Health and National Ethics Committee for Health Research of Senegal [35]. Informed written consent was initially obtained from individuals, parents or guardians of children and was regularly renewed.

\section{Sample collection and study design}

The samples used in this study were collected during a cross-sectional survey conducted at the village level in June 2016 (just before the malaria transmission season) in Ndiop. A venous blood sample was taken from each participant, and thick and thin blood smears were prepared for malaria diagnosis by microscopy. Plasma and blood pellets were separated and stored at $-20^{\circ} \mathrm{C}$ for serological and molecular analysis respectively.

The study involved 353 venous samples from individuals over 5 years of age. Children less than 5 years, whose blood was collected on capillary tubes, were excluded because DNA extraction required $200 \mu \mathrm{l}$ globular pellet. The microscopic parasite prevalence was determined by examination of thick and thin blood smears stained with Giemsa. The submicroscopic parasite prevalence was determined by real-time PCR (qPCR). In order to compare parasite prevalence and IgG seroprevalence, all 353 samples were tested for $\lg G$ against the crude schizont antigen of a local $P$. falciparum strain using the ELISA technique. A first set of 45 qPCR positive samples were genotyped at the $m s p-2$ locus to investigate parasite genetic diversity. A second set of age-matched cohort of 110 individuals between qPCR positive $(\mathrm{N}=55)$ and qPCR negative ( $\mathrm{N}=55)$ samples was used to analyze the impact of submicroscopic carriage of Plasmodium on the antibody responses. An age-stratified analysis was done with three age groups: under 10 years, $10-15$ years and over 15 years old.

\section{Microscopic examination}


Thick and thin smears were stained with $10 \%$ Giemsa for 25 minutes and microscopically examined for determination of parasite density and identification of Plasmodium species. The number of parasites per 200 white blood cells in thick films was recorded and parasite density was estimated by counting the number of leucocytes by field examined and by arbitrarily considering that 8,000 leucocytes were present in $1 \mu \mathrm{l}$ of blood. At least two hundred thick-film fields were examined before a slide was declared negative. Each slide was read by two experienced microscopists and in the case of a discrepancy, a third microscopist examined the slide. A slide was considered positive after two concordant readings.

\section{Molecular detection and characterization of Plasmodium species}

The detection of Plasmodium spp was carried out by qPCR following genomic DNA isolation of Plasmodium parasites using QIAamp DNA Blood Mini Kit (Qiagen, Hilden, Germany) according to manufacturer's instructions. Extraction was performed from $200 \mu \mathrm{l}$ of packed red blood cells, and. the DNA was recovered in $50 \mu$ l of elution buffer provided with the kit into a properly labelled $1.5 \mathrm{ml}$ Eppendorf tube and was stored at $-20^{\circ} \mathrm{C}$ until used.

Parasite diagnostic by qPCR was based on melt curve comparison against negative and positive controls using "screening real-time PCR" with genus-specific primers targeting the Plasmodium cytochrome $b$ gene [34]. Briefly, a $20 \mu \mathrm{lmix}$ was prepared with $4 \mu \mathrm{l}$ of 5X Evagreen qPCR Master Mix (Solis Biodyne), $0.3 \mu \mathrm{l}$ of each primer $(10 \mu \mathrm{M}), 5 \mu \mathrm{l}$ of genomic DNA and $10.4 \mu \mathrm{l}$ distilled water. Primers and running programs were as described by Carnier et al. [36].

Identification of Plasmodium species was carried out using a nested PCR technique with primers targeting the Plasmodium spp. 18S small sub-unit ribosomal RNA (18S ssrRNA) gene. A volume of $5 \mu \mathrm{l}$ from the primary PCR amplification with Plasmodium genus-specific rPLU 5 and rPLU6 primers pairs is used as a template for the second PCR. The primer pairs: rFAL1 and rFAL2 for $P$. falciparum, rVIV1 and rVIV2 for $P$. vivax, rOVA1 and rOVA2 for $P$. ovale and rMAL1 and rMAL2 for $P$. malariae were synthesized from TIB MOLbIOL (Germany). The PCR conditions were described by Zhou et al. 2014 [37]. The expected sizes for the different species were: $120 \mathrm{bp}$ for $P$. vivax, 144 bp for $P$. malariae, $205 \mathrm{bp}$ for $P$. falciparum, 375 bp for $P$. ovale.

\section{msp-2 genotyping}

DNA from 45 qPCR $P$. falciparum positive samples was genotyped by nested PCR amplification of the highly polymorphic region of $m s p-2$ gene (block 3 ) as described previously [38, 39]. All primers used were synthesized from Tib Molbiol (Germany). In the primary reaction, the primers used span the entire $m s p-2$ block 3. The initial amplification was followed by individual nested PCR reactions using primers specific for FC27 and 3D7 allelic families of $m s p-2$. In the first PCR, $5 \mu$ of DNA was amplified with $12.5 \mu \mathrm{l}$ of 2×GMM (Go Taq Green Master Mix, Catalogue no M7113 Promega), $1 \mu$ l of each primer $(10 \mu \mathrm{M})$ and sterile ultrapure water to a final volume of $25 \mu \mathrm{l}$. For the second PCR, $5 \mu \mathrm{l}$ of product from the first PCR was amplified using $12.5 \mu \mathrm{l}$ of $2 \times$ GMM (Go Taq Green Master Mix, M7113 Promega), $1 \mu$ of each primer $(10 \mu \mathrm{M})$ and sterile ultrapure water to a final volume of $25 \mu \mathrm{l}$. Positive and negative controls were 
included in each set of reactions. After amplification, $10 \mu \mathrm{l}$ of each PCR product were separated by electrophoresis on a $1.5 \%$ agarose gel that was stained with ethidium bromide. The size of the PCR products was estimated using a DNA ladder (1 kb Plus DNA ladder, Invitrogen). Amplified DNA was visualized by ultraviolet trans-illumination using an E-GEL IMAGER (Life Technologies). Gel photographs were re-scored by visual comparison of DNA fragments and genotypes were identified according to band sizes for each individual sample. The size polymorphism for each allelic family was analyzed assuming that one band represented one amplified PCR fragment derived from a single copy of $P$. falciparum msp2 gene.

\section{Antigen preparation and ELISA assay}

Crude schizont antigens from P. falciparum 0703 field-adapted strain [40] were prepared from in vitro continuous culture on $0+$ erythrocytes in RPMI medium containing $0.5 \%$ Albumax [41]. The parasites were incubated in an atmosphere of $5 \% \mathrm{CO} 2,5 \% \mathrm{O} 2$, and $90 \% \mathrm{~N} 2$ generated with an adjustable gasmixing device [42]. Schizonts stage parasites were harvested and lysed in three volumes of sterile distilled water and stored into aliquotes in liquid nitrogen [43]. The MSP3 antigen (clone T9/96) was an $E$. coli-expressed DG-210 purified protein 28 (kind gift from Dr C. Oeuvray) [44].The ELISA assay was performed as previously described [33, 44]. The 0703 crude extract was set to $1 / 3000$ dilution by a doseeffect assay using positive control sera. Maxisorp plates (Nunc, Roskilde, Denmark) were coated with 100 $\mu \mathrm{l}$ of diluted crude extracts antigen in phosphate-buffered saline (PBS, pH 7.4). Non-infected red blood cell extracts were also tested for non-specific binding. MSP3 antigen was diluted to $1 \mu \mathrm{g} / \mathrm{ml}$ in PBS and $100 \mu \mathrm{l}$ was used for coating the Immulon $4 \mathrm{HBX}$ plates (Thermo Fisher Scientific). All plates were incubated overnight at $4{ }^{\circ} \mathrm{C}$ and then washed four times with $200 \mu \mathrm{l} /$ well of washing buffer (PBS containing $0.05 \%$ Tween 20 ). The wells were then blocked with $150 \mu$ l of blocking buffer ( $3 \%$ skimmed milk in washing buffer) for 1 hour. Plasma samples were diluted at 1/200 in a dilution buffer ( $1 \%$ skimmed milk in PBS with $0.05 \%$ Tween and $0.03 \%$ sodium azide) and $100 \mu$ l of diluted sera were distributed in triplicate in the wells. Positive (a pool of 25 sera from clinically immune adults living in

Dielmo) and negative (a pool of non-immune Europeans) controls were included on each plate. Following incubation with sera and washing, polyclonal goat anti-human IgG (Life Technologies, USA) or goat antihuman IgM (Life technologies, USA) conjugated to peroxidase were added at a dilution of 1/6000 and $1 / 3000$ in the dilution buffer ( $1 \%$ skimmed milk in PBS-Tween $0.05 \%$ ) respectively. Bound peroxidase was detected with $100 \mu \mathrm{l}$ of substrate solution (TMB Solution; Thermo Fisher Scientific Inc.) for $30 \mathrm{~min}$ and the enzymatic reaction stopped by addition of $50 \mu \mathrm{l}$ of $0.2 \mathrm{mM}$ sulfuric acid. The optical density (OD) at $450 \mathrm{~nm}$ was read in a BIO-RAD Microplate Reader (iMark).

\section{Parameters definition and statistical analysis}

\section{Genetic parameters}


The frequency of allelic families was expressed as the percentage of fragments assigned to one allelic family or combination of allelic families out of the total number of fragments detected for $m s p-2$ gene. The complexity of infection (COI), also referred as the multiplicity of infection (MOI) or number of genotypes per infection was calculated by dividing the total number of fragments detected in $m s p-1$ or $m s p-2$ by the number of samples positive for the same marker. Multiple infections (MI) or polyclonal infections corresponded to the proportion of isolates with more than one amplified PCR fragment. Expected heterozygosity (HE) was defined as the probability of being infected by two parasites with different alleles at a given locus. Result of HE ranging from 0 to 1 was calculated by using the following formula: $\mathrm{HE}=[\mathrm{n} /(\mathrm{n}-1)]\left[\left(1-\sum \mathrm{pi}\right)\right]$, where $\mathrm{n}$ is the number of isolates sampled and $\mathrm{pi}$ is the allele frequency at a given locus.

\section{Immunological parameters}

Results were expressed as optical density (OD) ratio calculated as follow: mean OD sample/mean OD naive serum pool. Sera with an OD ratio $>2$ were considered as positive response for prevalence calculations [44] (Mbengue, B et al., 2019). Variations between tests for positive controls should not exceed $20 \%$. The Plate to plate reproducibility was considered satisfactory with coefficients of variation not exceeding $4 \%$ using two positive controls, two negative controls and the same antigen for each plate.

\section{Statistical analysis}

Association between the prevalence of sub-microscopic $P$. falciparum carriage (qPCR+) and seroprevalence (lgG+ against crude schizont extract of strain 0703) was analyzed using the chi-square test. Mean OD ratio differences between qPCR positive and QPCR negative groups were calculated using Student's t-test. Differences were considered significant when p-value was less than 0.05 . All analyses were performed using R software (version 3.6.1).

\section{Results}

\section{Prevalence, seroprevalence and genetic diversity of malaria infections in Ndiop 2016}

The 353 individuals considered in the study were divided into three age groups: under 10 years, 10-15 years and over 15 years old comprising 74, 63 and 216 individuals, respectively. The sex ratio was 2 in favor of females (Table 1). None of the subjects had fever at the time of sampling. The microscopic diagnosis was negative for all thick smears defining a study cohort of submicroscopic asymptomatic individuals. An asymptomatic malaria infection was defined as the presence of parasites of the genus Plasmodium in an individual in absence of clinical manifestations or antimalarial treatment. $P$. falciparum was the only species detected by nested PCR technique.

Table 1: Demographic characteristics of Ndiop cross-sectional sampling in 2016, the ELISA age matched PCR (+)/ PCR (-) set and genotyped samples 


\begin{tabular}{|c|c|c|c|c|c|c|}
\hline & & \multirow[t]{2}{*}{ Number } & \multirow{2}{*}{$\begin{array}{l}\text { Sex ratio } \\
\mathrm{F} / \mathrm{H}\end{array}$} & \multicolumn{3}{|c|}{ Age groups (year) } \\
\hline & & & & $<10$ & $10-15$ & $>15$ \\
\hline \multicolumn{6}{|l|}{ cross-sectional sampling } & 216 \\
\hline Genotyped samples & $\mathrm{PCR}+$ & 45 & 3.2 & 15 & 13 & 17 \\
\hline \multirow[t]{2}{*}{ ELISA: age matched PCR (+)/ PCR (-) } & PCR+ & 55 & 3.4 & 17 & 15 & 23 \\
\hline & PCR- & 55 & 1.7 & 17 & 15 & 23 \\
\hline
\end{tabular}

The overall parasite prevalence obtained by qPCR was $22.37 \%$ (79/353). The distribution of this prevalence was $8.5 \%$ (30/353), 4.5\% (16/353), 9.3\% (33/353) for children under 10 years, 10 to 15 years, and above 15 years old, respectively. There was a significant difference in qPCR parasite prevalence between age group 10-15 years and the two other age groups; under 10 years (Chi-square test, $p=0.03$ ) and over 15 years (Chi-square test, $p=0.01$ ).

The global IgG seroprevalence against the crude schizont antigen was 34.8\% (123/353). The repartition of the seroprevalence by age group was $6.2 \%$ (22/353), $4.8 \%$ (17/353), $23.8 \%$ (84/353) for children under 10 years, 10 to 15 years, and above 15 years old, respectively. Seroprevalence was significantly higher for the age group over 15 years compared to the other two age groups ( $p=0.0001$, Chi-square test).

Parasite prevalence and IgG seroprevalence were strongly related for age groups below 15 years of age. However, above 15 years of age, a significant difference was found between parasite prevalence of $9.3 \%$ $(33 / 353)$ and $\operatorname{lgG}$ seroprevalence of 23.8\% (84/353) ( $p=0.01$, Chi-square test) (Figure 1).

The genotyping of $m s p-2$ marker was performed on samples from 45 P. falciparum positive individuals. Genotyping was successful in 42 samples distributed as follows: 15,13 and 14 samples for age groups under 10 years, 10-15 years and over 15 years old d, respectively (Table 1 ). The results revealed a complexity of infection (COI) of 2.4. A total of 17 different alleles were detected, 12 for the allelic family FC27 and 5 for 3D7. The frequencies of the allelic families FC27, 3D7 or the combination of FC27/3D7 allelic families were $28.6 \%(12 / 42), 11.9 \%$ (5/42), and $59.5 \%$ (25/42), respectively. The expected heterozygosity (HE) of the sub-microscopic carriage for the $m s p-2$ marker was 0.49 , and the prevalence of multiple infections (MI) was 73.8\% (31/42) (Table 2).

Table 2 Allelic diversity of Plasmodium falciparum msp-2 gene 


\begin{tabular}{|l|l|}
\hline Allelic families & $\mathbf{N}(\%)$ \\
\hline FC27 & $12(2.6)$ \\
\hline 3D7 & $5(1.9)$ \\
\hline FC27/3D7 & $25(59.5)$ \\
\hline Total combinations & $\mathbf{4 2 ( 1 0 0 )}$ \\
\hline Number of different alleles & $16(11$ FC27, 5 3D7) \\
\hline Expected heterozygosity (HE) & 0.49 \\
\hline Multiple infections (MI) & $31(73.8)$ \\
\hline Complexity of infection (COI) & 2.4 \\
\hline
\end{tabular}

\section{Contribution of sub-microscopic parasite carriage on immune responses}

To assess the impact of submicroscopic parasite carriage on antibody responses to malaria, the levels of circulating antibodies against the crude extract of P.falciparum local strain and MSP-3 recombinant antigen were analyzed. This analysis was conducted on an age-matched cohort of 55 parasite-free individuals and 55 parasite submicroscopic carriers from the three defined groups $(<10,10-15$, and $>15$ years). It is important to note that, the cohort was limited to 110 individuals as this was the maximum number that could be matched and only age parameter was taken into account. Interestingly, the level of circulating IgM, reflecting a recent infection, was significantly higher $(p=0.034$, Student t-test) in young children infected (below 10 years) whereas there was no significant difference in older children and adults (Figure 2). The level of circulating IgG was significantly lower in adults carrying parasite for both crude schizont extract ( $p=0.021$, Student t-test) (Figure 3 ) and MSP-3 recombinant antigen $(p=0.034$, Student t-test) (Figure 4). In contrast, IgG level was comparable in children (10 and $10-15$ years) independently of the presence of parasite (Figures 3,4 ). All together, these results suggest that submicroscopic carriage of $P$. falciparum is accompanied by a progressive establishment of a tolerance toward the parasite.

\section{Discussion}

The study focused on the contribution of asymptomatic submicroscopic $P$. falciparum carriage to immune responses. The level of antibody compared between submicroscopic carriers (qPCR positive and microscopy negative) and age-matched non-P. falciparum carriers (qPCR negative and microscopy negative) shows clearly acquisition of immune tolerance to carried parasites for elders population (over 15 years). 
The results showed significantly lower antibody levels in $P$. falciparum carriers over 15 years of age compared to non-carriers of the same age group for IgG against crude schizont and MSP-3 recombinant antigen. For age groups under 15 years, however, antibody levels did not differ significantly between $P$. falciparum carriers and non-carriers, except for IgM responses, which were significantly elevated in parasite carriers under 10 years of age, indicating a greater sensitivity to primary infection. These results indicate that individuals over 15 years of age have not developed significant immune responses against carried parasites reflecting the possible immune tolerance to malaria that was mentioned very early in a previous study [45]. The main argument based on the difference in clinical manifestations between naive and immune individuals from endemic areas $[46,47]$ is expressed the molecular level by different rates of pro-inflammatory cytokines between naïve and immune subjects [48].

This immune tolerance is also supported by the first series of experimental malaria infections in humans, which revealed that the risk of fever decreases with the number of infections [49]. According to Shanks [50], parasites in asymptomatic carriage benefit from relative immune tolerance and adults exercise better control over parasite density and genotypic fluctuations. Indeed, antibodies can be classified into two groups, those acquired during early childhood, resulting from the primary infection, short-lived in nature, considered as marker of exposure and those with a long lifespan acquired through repeated infections and associated with protection $[51,52,53]$. Longer-lasting antibodies are produced by either long-lived plasma cells or long memory B cells $[54,55]$. Accordingly, in this study, in contrast to those over 15 years of age, prevalence and seroprevalence were closely related in children under 15 years of age. It was also reported that the occurrence of a clinical episode corresponds to the emergence of a new genotype [56] and that the genetic characteristics of the parasite populations detected during phases of asymptomatic carriage differed from those causing a clinical episode [57].

One possible mechanism for parasite tolerance could be through clonal selection in immune adults which has been reported by Ntoumi et al. [58], who have showed that the number of genotypes and allelic families per positive sample is significantly reduced around the age of 15 years in endemic areas. The present study showed that submicroscopic $P$. falciparum infection was associated with a low COI (2.4) confirming those obtained by A-Elbasit et al. ( $\mathrm{COI}=1.0$ with $m s p-2$ marker) and Gueye et al. (COI=1.4 and 1.7 for less than 5 years old and over 5 years old, respectively, with $m s p-1$ marker) $[62,63]$. Among the two types of antigens tested, the crude antigen was more sensitive than the MSP-3 recombinant antigen [33]. The results pointed out the limitations of the ELISA test for analysis of seroprevalence, based on the recombinant antigen, in the context of low parasite densities with substantially reduced response amplitudes.

\section{Conclusion}

The study showed that asymptomatic submicroscopic $P$. falciparum carriage is associated with immune tolerance reflected by a decrease in IgG antibody responses for adult parasite carriers over 15 years of age. The study therefore underlines the particular attention to be paid to asymptomatic submicroscopic malaria in adults as a stable parasite reservoir in a context of malaria pre-elimination. Since the immune 
system is tolerant to parasites at the submicroscopic level, molecular detection followed by treatment could be a valuable method for achieving elimination.

\section{Abbreviations}

IRS: Indoor Residual Spraying

ACT: Artemisinin-based Combination Therapies

ITN: Insecticide-Treated Nets

LLIN: Long-Lasting Insecticide-treated Nets

msp 1: merozoite surface protein 1

msp2: merozoite surface protein 2

EIR: Entomological Inoculation Rate

DNA: deoxyribonucleic acid

PCR: Polymerase Chain Reaction

qPCR: quantitative real-time PCR

UV: ultraviolet

COI: Complexity Of Infection

MOI: Multiplicity Of Infection

MI: Multiple Infections

bp: base pairs

HE: Expected Heterozygosity

P. falciparum: Plasmodium falciparum

\section{Declarations}

\section{Ethics approval and consent to participate}

The study protocol was approved by the National Ethics Committee for Health Research of Senegal (CNERS). Written informed consent was obtained from parents or guardians of the children prior to 
recruitment. For those who were not literate, the protocol was translated into the local language, and consent was obtained in the presence of an independent witness.

\section{Consent for publication}

“Not applicable"

\section{Availability of data and material}

The datasets analysed during the current study are available from the corresponding author on reasonable request.

\section{Competing interests}

The authors declare that they have no competing interests

\section{Funding}

This study was supported by Foundation Institut Pasteur de Dakar.

\section{Authors' contributions}

BD conceived the study, contributed to the fieldwork, performed laboratory experiments and data analysis, and drafted the manuscript. MN participated in the design of the study, and contributed to the fieldwork and the conduct of the molecular biology assays. ATB coordinated the study and contributed to the study design. FD, YD, AT, ID, and IVW contributed to data analysis and the revision of the manuscript. AFM contributed to the laboratory experiments. RP contributed to the methodology, contributed to drafting and revising the manuscript. CT participated in the statistical analysis. FDS and JF coordinated the fieldwork and the collection of samples, and managed the database. MS contributed to the methodology, participated in revising the manuscript and approved the final version. All authors contributed to the revision of the manuscript, read and approved the final manuscript.

\section{Acknowledgements}

The authors would like to thank all the stakeholders involved in this study, and particularly PD staff Dr Ndeye Sakha BoB for contributing with reagents, the inhabitants of Ndiop village, the local health workers and authorities. The authors gratefully acknowledge the Foundation Institut Pasteur de Dakar, the National Health Ministry and Cheikh Anta Diop University.

\section{References}

1. World malaria report 2019. Geneva: World Health Organization; 2019.

2. Gething PW, Casey DC, Weiss DJ, Bisanzio D, Bhatt S, Cameron E, et al. Mapping Plasmodium falciparum mortality in Africa between 1990 and 2015. N Engl J Med. 2016;375:2435-45. 
3. Bhatt S, Weiss DJ, Cameron E, Bisanzio D, Mappin B, Dalrymple U, et al. The effect of malaria control on Plasmodium falciparum in Africa between 2000 and 2015. Nature. 2015;526:207-11.

4. Hemingway J, Ranson H, Magill A, Kolaczinski J, Fornadel C, Gimnig J, et al. Averting a malaria disaster: will insecticide resistance derail malaria control? Lancet. 2016;387:1785-8.

5. Beier JC, Killeen G, Githure Jl. Entomologic inoculation rates and Plasmodium falciparum malaria prevalence in Africa. Am J Trop Med Hyg. 1999;61:109-13.

6. Kelly-Hope LA, McKenzie FE. The multiplicity of malaria transmission: a review of entomological inoculation rate measurements and methods across sub-Saharan Africa. Malar J. 2009;8:19.

7. Fontenille D, Lochouarn L, Diagne N, Sokhna C, Lemasson JJ, Diatta M, et al. High annual and seasonal variations in malaria transmission by anophelines and vector species composition in Dielmo, a holoendemic area in Senegal. Am J Trop Med Hyg. 1997;56:247-53.

8. Robert V, Macintyre K, Keating J, Trape JF, Duchemin JB, Warren M, et al. Malaria transmission in urban sub-Saharan Africa. Am J Trop Med Hyg. 2003;68:169-76.

9. Elissa N, Migot-Nabias F, Luty A, Renaut A, Touré F, Vaillant M, et al. Relationship between entomological inoculation rate, Plasmodium falciparum prevalence rate, and incidence of malaria attack in rural Gabon. Acta Trop. 2003;85:355-61.

10. Drakeley CJ, Corran PH, Coleman PG, Tongren JE, McDonald SLR, Carneiro I, et al. Estimating medium- and long-term trends in malaria transmission by using serological markers of malaria exposure. Proc Natl Acad Sci USA. 2005;102:5108-13.

11. Stewart L, Gosling R, Griffin J, Gesase S, Campo J, Hashim R, et al. Rapid assessment of malaria transmission using age-specific sero-conversion rates. PLoS ONE. 2009;4:e6083.

12. Cornille-Brögger R, Mathews HM, Storey J, Ashkar TS, Brögger S, Molineaux L: Changing patterns in the humoral immune response to malaria before, during, and after the application of control measures: a longitudinal study in the West African savanna. Bull World Health Organ. 1978, 56: 579600.

13. Cook J, Kleinschmidt I, Schwabe C, Nseng G, Bousema T, Corran PH, et al. Serological markers suggest heterogeneity of effectiveness of malaria control interventions on Bioko Island, equatorial Guinea. PLoS ONE. 2011;6:e25137.

14. Esposito F, Lombardi S, Modiano D, Zavala F, Reeme J, Lamizana L, Coluzzi M, Nussenzweig RS. Prevalence and levels of antibodies to the circumsporozoite protein of Plasmodium falciparum in an endemic area an their relationship to resistance against malaria infection. Trans R Soc Trop Med Hyg. 1988;82: 827-832.

15. Ramasamy R, Nagendran K, Ramasamy MS: Antibodies to epitopes on merozoite and sporozoite surface antigens as serologic markers of malaria transmission: studies at a site in the dry zone of Sri Lanka. Am J Trop Med Hyg. 1994, 50: 537-547.

16. Sharp BL, Kleinschmidt I, Streat E, Maharaj R, Barnes KI, Durrheim DN, et al. Seven years of regional malaria control collaboration-Mozambique, South Africa, and Swaziland. Am J Trop Med Hyg. 2007;76:42-7. 
17. Baum E, Sattabongkot J, Sirichaisinthop J, Kiattibutr K, Jain A, Taghavian O, et al. Common asymptomatic and submicroscopic malaria infections in Western Thailand revealed in longitudinal molecular and serological studies: a challenge to malaria elimination. Malar J. 2016;15:333.

18. Katrak S, Nayebare P, Rek J, Ariaitwe E, Nankabirwa J, Kamya M, et al. Clinical consequences of submicroscopic malaria parasitaemia in Uganda. Malar J. 2018;17:67.

19. Chiu CY, Hodder AN, Lin CS, Hill DL, Li Wai Suen CS, Schofield L, et al. Antibodies to the Plasmodium falciparum proteins MSPDBL1 and MSPDBL2 opsonize merozoites, inhibit parasite growth, and predict protection from clinical malaria. J Infect Dis. 2015;212:406-15.

20. Kana IH, Garcia-Senosiain A, Singh SK, Tiendrebeogo RW, Chourasia BK, Malhotra P, et al. Cytophilic antibodies against key Plasmodium falciparum blood stage antigens contribute to protection against clinical malaria in a high transmission region of Eastern India. J Infect Dis. 2018;218:95665.

21. Irani V, Ramsland PA, Guy AJ, Siba PM, Mueller I, Richards JS, et al. Acquisition of functional antibodies that block the binding of Erythrocyte-Binding Antigen 175 and protection against Plasmodium falciparum malaria in children. Clin Infect Dis. 2015;61:1244-52.

22. Hill DL, Wilson DW, Sampaio NG, Eriksson EM, Ryg-Cornejo V, Harrison GLA, et al. Merozoite antigens of Plasmodium falciparum elicit strain-transcending opsonizing immunity. Infect Immun. 2016;84:2175-84.

23. Reiling L, Boyle MJ, White MT, Wilson DW, Feng G, Weaver R, et al. Targets of complement-fixing antibodies in protective immunity against malaria in children. Nat Commun. 2019;10:610.

24. O'Flaherty K, Maguire J, Simpson JA, Fowkes FJI. Immunity as a predictor of anti-malarial treatment failure: a systematic review. Malar J. 2017;16:158.

25. Elliott SR, Fowkes FJ, Richards JS, Reiling L, Drew DR, Beeson JG. Research priorities for the development and implementation of serological tools for malaria surveillance. F1000Prime Rep. 2014;6:100.

26. King CL, Davies DH, Felgner P, Baum E, Jain A, Randall A, et al. Biosignatures of exposure/transmission and immunity. Am J Trop Med Hyg. 2015;93:15-37.

27. Riley EM, Stewart VA. Immune mechanisms in malaria: new insights in vaccine development. Nat Med. 2013;19:168-78.

28. Miller LH, Ackerman HC, Su XZ, Wellems TE. Malaria biology and disease pathogenesis: insights for new treatments. Nat Med. 2013;19:156-67.

29. Trape JF, Rogier C, Konate L, Diagne N, Bouganali H, Canque B, et al. The Dielmo project: a longitudinal study of natural malaria infection and the mechanisms of protective immunity in a community living in a holoendemic area of Senegal. Am J Trop Med Hyg. 1994;51:123-37.

30. Rogier C, Trape JF. Study of premunition development in holo- and meso-endemic malaria areas in Dielmo and Ndiop (Senegal): preliminary results, 1990-1994. Med Trop. 1995;55:71-6

31. Trape JF, Tall A, Sokhna C, Ly AB, Diagne N, Ndiath O, et al. The rise and fall of malaria in a West African rural community, Dielmo, Senegal, from 1990 to 2012: a 22 year longitudinal study. Lancet 
Infect Dis. 2014;4:476-88.

32. Trape JF, Rogier C. Combating malaria morbidity and mortality by reducing transmission. Parasitol Today. 1996;12:236-40.

33. Diop F, Richard V, Diouf B, Sokhna C, Diagne N, Trape JF, et al. Dramatic declines in seropositivity as determined with crude extracts of Plasmodium falciparum schizonts between 2000 and 2010 in Dielmo and Ndiop, Senegal. Malar J. 2014;13:83.

34. Niang M, Thiam LG, Sane R, Diagne N, Talla C, Doucoure S, et al. Substantial asymptomatic submicroscopic Plasmodium carriage during dry season in low transmission areas in Senegal: implications for malaria control and elimination. PLoS ONE. 2017;12:e0182189.

35. Trape JF, Rogier C, Konate L, Diagne N, Bouganali H, Canque B, et al. The Dielmo project: a longitudinal study of natural malaria infection and the mechanisms of protective immunity in a community living in a holoendemic area of Senegal. Am J Trop Med Hyg. 1994;51:123-37.

36. Canier L, Khim N, Kim S, Sluydts V, Heng S, Dourng D, et al. An innovative tool for moving malaria PCR detection of parasite reservoir into the field. Malar J. 2013;12:405.

37. Zhou X, Huang J-L, Njuabe MT, Li S-G, Chen J-H, Zhou X-N. A molecular survey of febrile cases in malaria-endemic areas along China-Myanmar border in Yunnan province, People's Republic of China. Parasite. 2014;21:27.

38. Snounou G, Zhu X, Siripoon N, Jarra W, Thaithong S, Brown KN, et al. Biased distribution of msp1 and msp2 allelic variants in Plasmodium falciparum populations in Thailand. Trans R Soc Trop Med Hyg. 1999;93:369-74.

39. Diouf B, Diop F, Dieye Y, Loucoubar C, Dia I, Faye J, et al. Association of high Plasmodium falciparum parasite densities with polyclonal microscopic infections in asymptomatic children from Toubacouta, Senegal. Malaria journal. 2019;18:48.

40. Aribot G, Rogier C, Sarthou JL, Trape JF, Balde AT, Druilhe P, et al. Pattern of immunoglobulin isotype response to Plasmodium falciparum blood-stage antigens in individuals living in a holoendemic area of Senegal (Dielmo, West Africa). Am J Trop Med Hyg. 1996;54:449-57.

41. Jensen JB, Trager W. Plasmodium falciparum in culture: use of outdated erthrocytes and description of the candle jar method. J Parasitol. 1977;63:883-6

42. Bei AK, Patel SD, Volkman SK, Ahouidi AD, Ndiaye D, Mboup S, et al. An adjustable gas-mixing device to increase feasibility of in vitro culture of Plasmodium falciparum parasites in the field. PLoS One. 2014; 9:e90928.

43. Perraut R, Guillotte M, Drame I, Diouf B, Molez JF, Tall A, et al. Evaluation of anti-Plasmodium falciparum antibodies in Senegalese adults using different types of crude extracts from various strains of parasite. Microbes Infect. 2002;4:31-5.

44. Mbengue B, Fall MM, Varela ML, Loucoubar C, Joos C, Fall B, et al. Analysis of antibody responses to selected Plasmodium falciparum merozoite surface antigens in mild and cerebral malaria and associations with clinical outcomes. Clin Exp Immunol. 2019;196:86-96. 
45. Sinton JA. Immunity or Tolerance in Malarial Infections: (Section of Comparative Medicine) Proc R Soc Med. 1938;31:1298-302.

46. Marsh K, Kinyanjui S. Immune effector mechanisms in malaria. Parasite Immunol.2006;28:51-60.

47. Ademolue TW, Aniweh Y, Kusi KA, Awandare GA. Patterns of inflammatory responses and parasite tolerance vary with malaria transmission intensity. Malar J. 2017;16:145.

48. Schofield L, Grau GER. Immunological processes in malaria pathogenesis. Nat Rev Immunol. 2005;5:722-35.

49. Collins WE, Jeffery GM. A retrospective examination of secondary sporozoite-and trophozoiteinduced infections with Plasmodium falciparum: development ofparasitologic and clinical immunity following secondary infection. Am J Trop Med Hyg. 1999;61:20-35.

50. Shanks GD. Tolerance may be more appropriate than immunity when describing chronic malaria infections. Am J Trop Med Hyg. 2019;100: 497-500.

51. Chan JA, Stanisic DI, Duffy MF, Robinson LJ, Lin E, Kazura JW, et al. Patterns of protective associations differfor antibodies to $P$. falciparum-infected erythrocytes and merozoites in immunity against malaria in children. Eur J Immunol. 2017;47:2124-2136.

52. Yman V, White MT, Asghar M, Sundling C, Sonden K, Draper SJ, et al. Antibody responses to merozoite antigens after natural Plasmodium falciparum infection: kinetics and longevity in absence of re-exposure. BMC Med. 2019;17:22.

53. McCallum FJ, Persson KEM, Fowkes FJI, Reiling L, Mugyenyi CK, Richards JS, et al. Differing rates of antibody acquisition to merozoite antigens in malaria: implications for immunity and surveillance. $J$ Leukoc Biol. 2017;14:913-25.

54. Akpogheneta OJ, Duah NO, Tetteh KKA, Dunyo S, Lanar DE, Pinder M, et al. Duration of naturally acquired antibody responses to blood-stage Plasmodium falciparum is age dependent and antigen specific. Infect Immun. 2008;76:1748-55.

55. Ndungu FM, Lundblom K, Rono J, Illingworth J, Eriksson S, Farnert A. Long-lived Plasmodium falciparum specific memory B cells in naturally exposed Swedish travelers. Eur J Immunol. 2013;43:2919-29

56. Roper C, Richardson W, Elhassan IM, Giha H, Hviid L, Satti GMH, et al. Seasonal changes in the Plasmodium falciparum population in individuals and their relationship to clinical malaria: a longitudinal study in a Sudanese village. Parasitology. 1998;116: 501-510.

57. Contamin, $\mathrm{H}$. et al. Different genetic characteristics of Plasmodium falciparum isolates collected during successive clinical malaria episodes in Senegalese children. Am J Trop Med Hyg 54, 632-643 (1996).

58. Ntoumi F, Contamin H, Rogier C, Bonnefoy S, Trope JF, Mercereau-Puijalon O. Age dependent carriage of multiple Plasmodium falciparum merozoite surface antigen-2 alleles in asymptomatic malaria infection. Am J Trop Med Hyg. 1995;52:81-8.

59. Warimwe GM, Recker M, Kiragu EW, Buckee CO, Wambua J, Musyoki JN, et al. Plasmodium falciparum vargene expression homogeneity as a marker of the host-parasite relationship under 
different levels of naturally acquired immunity to malaria. PLoS ONE. 2013;8:e70467.

60. Wang CW, Hermsen CC, Sauerwein RW, Arnot DE, Theander TG, Lavstsen T. The Plasmodium falciparum vargene transcription strategy at the onset of blood stage infection in a human volunteer. Parasitol Int. 2009;58:478-80.

61. Bachmann A, Bruske E, Krumkamp R, Turner L, Wichers JS, Petter M, et al. Controlled human malaria infection with Plasmodium falciparum demonstrates impact of naturally acquired immunity on virulence gene expression. PLoS Pathog. 2019;15:e1007906.

62. A-Elbasit IE, ElGhazali G, A-Elgadir TM, Hamad AA, Babiker HA, Elbashir MI, et al. Allelic polymorphism of MSP2 gene in severe falciparum malaria in an area of low and seasonal transmission. Parasitol Res. 2007;102:29-34

63. Gueye NSG, Ntoumi F, Vouvoungui C, Kobawila SC, NKombo M, Mouanga AM, et al. Plasmodium falciparum merozoite protein-1 genetic diversity and multiplicity of infection in isolates from Congolese children consulting in a pediatric hospital in Brazzaville. Acta Trop.2018;183:78-83.

\section{Figures}

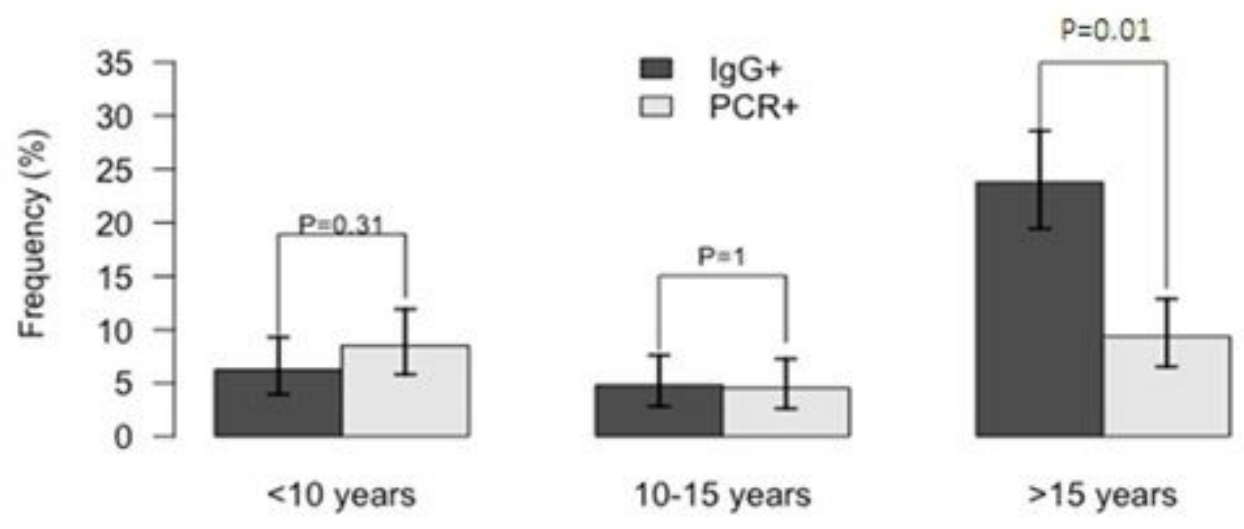

Figure 1

Association between qPCR-determined parasite prevalence (PCR+) and IgG seroprevalence (IgG+) against crude schizont antigen according to age groups. 


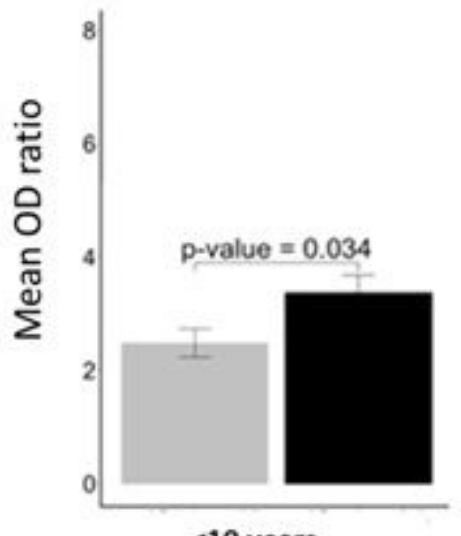

$<10$ years

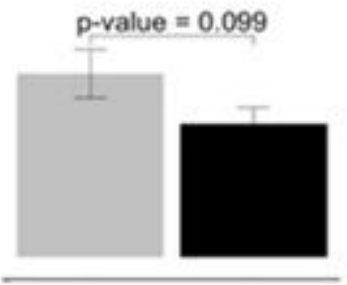

10-15 years

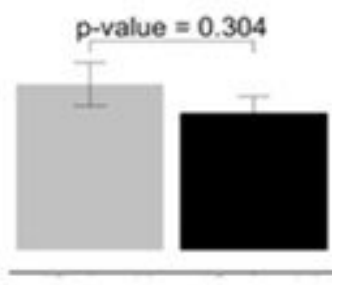

$>15$ years

\section{Figure 2}

Levels of circulating IgM antibodies against crude schizont extract antigen in age-matched groups $<10$ years, $10-15$ years and $>15$ years. Results expressed as mean OD ratios are shown for infected (PCR+) and non-infected (PCR-) individuals.

\section{IgG/crude antigen 0703}

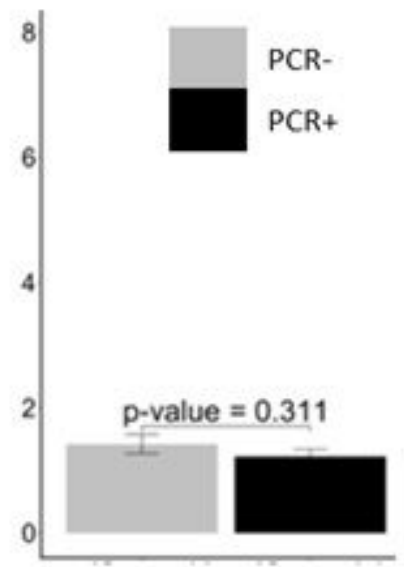

$<10$ years

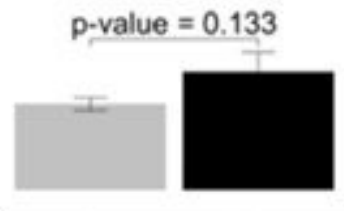

10-15 years

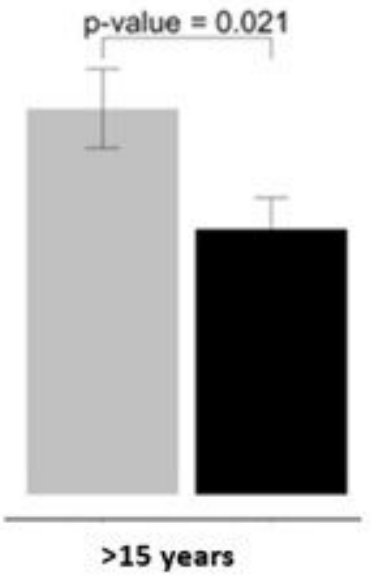

\section{Figure 3}

Levels of circulating IgG antibodies against crude schizont extract antigen in age-matched groups $<10$ years, $10-15$ years and >15 years. Results expressed as mean OD ratios are shown for infected (PCR+) and non-infected (PCR-) individuals. 


\section{IgG/recombinant MSP-3}

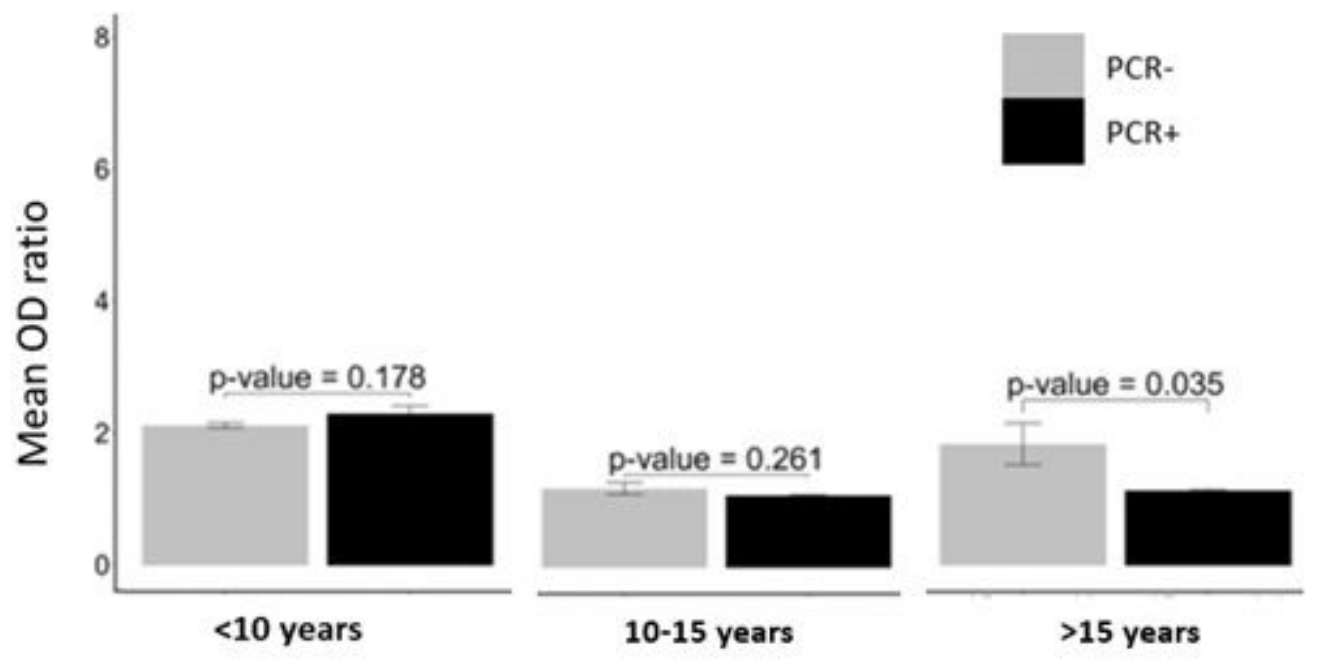

Figure 4

Levels of circulating IgG antibodies against the MSP-3 recombinant antigen in age-matched groups $<10$ years, $10-15$ years and $>15$ years. Results expressed as mean OD ratios are shown for infected (PCR+) and non-infected (PCR-) individuals. 